\title{
A Flipped Learning Agile Methodology for teaching in higher education levels
}

\author{
Jesús Águila-León ${ }^{a}$, Carlos Vargas-Salgado ${ }^{b}$, David Ribó-Pérez ${ }^{c}$, Paula Bastida \\ Molina $^{\mathrm{d}}$ \\ ${ }^{a}$ Departamento de Estudios del Agua y la Energía, Universidad de Guadalajara, México, \\ jesus.aguila@academicos.udg.mx , ${ }^{b}$ Departamento de Ingeniería Eléctrica, Universitat Politècnica de \\ València, Valencia, España, carvarsa@upvnet.upv.es , 'Instituto Universitario de Ingeniería \\ Energética, Camino de Vera s/n, Edificio 8E, $2^{\mathrm{a}}$ planta, Universitat Politècnica de València, Valencia, \\ Spain, david.ribo@iie.upv.es, Instituto Universitario de Ingeniería Energética, Camino de Vera s/n, \\ Edificio 8E, $2^{\mathrm{a}}$ planta, Universitat Politècnica de València, Valencia, Spain, paubasmo@etsid.upv.es
}

\section{Abstract}

This paper presents the results of implementing the Flipped Learning Agile (FLA) methodology as a general framework to manage courses and to encourage proactive learning for students in higher education levels. Flipped Learning is used in combination with Information and Communication Technologies (ICTs) to encourage the student in the self-learning process. It is proposed the integration of an Agile Methodology that includes the use of Scrum and Kanban methodologies, by means of sprints for task scheduling and using a board for activities status, into a Flipped Learning (FL) environment. The proposed FL environment is composed of applications such as YouTube, Google Classroom, and Google Drive. The Scrum methodology was designed for 4 sprints, each one for a week-long. Before applying the FLA methodology, a Motivated Strategies for Learning Questionnaire (MSLQ) was applied in a group of Electrical Circuits students at the University of Guadalajara. To examine the self-regulated learning process, the performance of the students was analysed before applying the FLA methodology; the same MSLQ was carried out after implementing the FLA methodology. The analyses of the last MSLQ show that the implementation of the FLA methodology, by means of the integration of the Agile methodologies of Scrum and Kanban into a flipped learning environment, encourage the self-learning strategy for higher education level students.

Keywords: Flipped Learning, Agile Methodology, Scrum, Kanban, Learning strategies, sprints, Peer-learning. 


\section{Introduction}

Agile methodologies have improved project development in the industry. The Agile Manifesto (Schwaber, 2004) settled down a development paradigm introducing Scrum and Kanban methodologies (Maximini, 2015; Stellman \& Greene, 2016) leading to a faster and more efficient project management. Scrum frameworks allow the completion of complex projects by dividing them into small time-lapsed tasks called sprints (Tracy, Frog, \& Power, 2014); while Kanban boards are meant to organize these tasks into a categorized status list of activities in the form of a planned task board (Hammarberg \& Sundén, 2013; Leopold \& Kaltenecker, 2015).

Agile methodologies have probed to improve project management in software engineering fields (Ahmad, Dennehy, Conboy, \& Oivo, 2018) as well as in product-service systems (Hernandez, Version, \& Hernandez, 2019). Recently, Industry 4.0, which can be defined as the integration of Internet of Things, Big Data and Artificial Intelligence into traditional industry (Vaidya, Ambad, \& Bhosle, 2018; Xu, Xu, \& Li, 2018), has started to make an extensive use of agile methodologies (Cakmakci et al., 2019).

There are also efforts for applying agile methodologies in Education fields. In the work of (Fernanda et al., 2018), a case of study in Universidad Técnica Particular de la Loja in Ecuador, is presented to apply agile methodologies in their teaching-learning process for engineering. Authors present a scrum based framework to plan, develop and follow-up academic activities. As a result, their students became more efficient and self-satisfied, with a higher interaction level in teamwork, as they were actively involved in more stages of the teaching-learning processes than in the traditional method. Also in (Fernanda et al., 2018) is presented an adaptation of the Agile Manifesto principles into the Academic field. Other authors have explored the potential, and evaluate the benefits, of agile methodologies and lean concepts to design teaching units, as (Judd \& Blair, 2018) presented in their case of study for an Australian university which adopted these strategies. They found that peerlearning was encouraged in students. Peer-learning is a process where students are stimulated to collaborative learning and efficient teamwork (Nielsen, Johansen, \& Jørgensen, 2018). As in agile methodologies is needed to work in teams, peer-learning becomes very important.

There are many instruments to encourage peer-learning. Recently Information and Communication Technologies (ICTs) had led to a Flipped Learning classroom environments for individual and collaborative online work. The authors in (BasooAránguiz, 2018) present a variety of online tools, like Google Classroom, YouTube, Google Drive, as a technological framework for a Flipped Learning (FL) environment 
methodology to promote peer-learning and self-regulated learning strategies (Broadbent \& Poon, 2015).

In this paper, it is presented a combined Flipped Learning and Agile (FLA) methodology applied to a case of study for a final project in a group of students for the course of Applied Electrical Circuits at the Universidad de Guadalajara, México. Improvements in student performance were measured by applying a Motivated Strategies for Learning Questionnaire (MSLQ) before and after implementing the FLA methodology.

The objectives of this work are as follow:

- To apply an FL environment to academic activities for a higher education level assignments.

- To apply the Agile methodology, the Scrum framework, and Kanban boards, for the student's activities.

- To obtain and analyze students self-learning and motivational learning beliefs indicators before and after applying the FLA methodology.

\section{Research methodology and implementation}

The methodology used is based on a Flipped Learning (FL) environment as presented (Basoo-Aránguiz, 2018), using the online Google Classroom suite as the course management platform, where the professor can publish and evaluate assignments as well as course additional material publishing. Also YouTube and Google Drive were incorporated into the Flipped Learning environment model presented. The inclusion of Agile methodologies was implemented by means of a Scrum framework and a Kanban board for the final course project. The student's performance is evaluated by a Motivated Strategies for Learning Questionnaire (MSLQ) before and after the FLA is implemented. As a case of study, the methodology was applied for $4^{\text {th }}$-semester students of Engineering in Energy at the Universidad de Guadalajara in the Applied Electric Circuits course. The student's group was composed of 23 students (18 men and 5 women aged 19 to 31 years old).

The Applied Electric Circuit course program is divided into five thematic units. For the case of study, in order to apply the FLA methodology, it is proposed a new sixth unit to integrate the Scrum framework and Kanban board as well as the MSLQ as a student's selfregulated learning strategies and motivational beliefs assessment.

Tools in face-to-face lectures and online work, such as Google Classroom, Google Drive and YouTube, were used as a flipped learning environment to accomplish the Scrum 
framework and Kanban boards tasks. Figure 1 shows the FLA methodology adaptation proposed for academic fields.
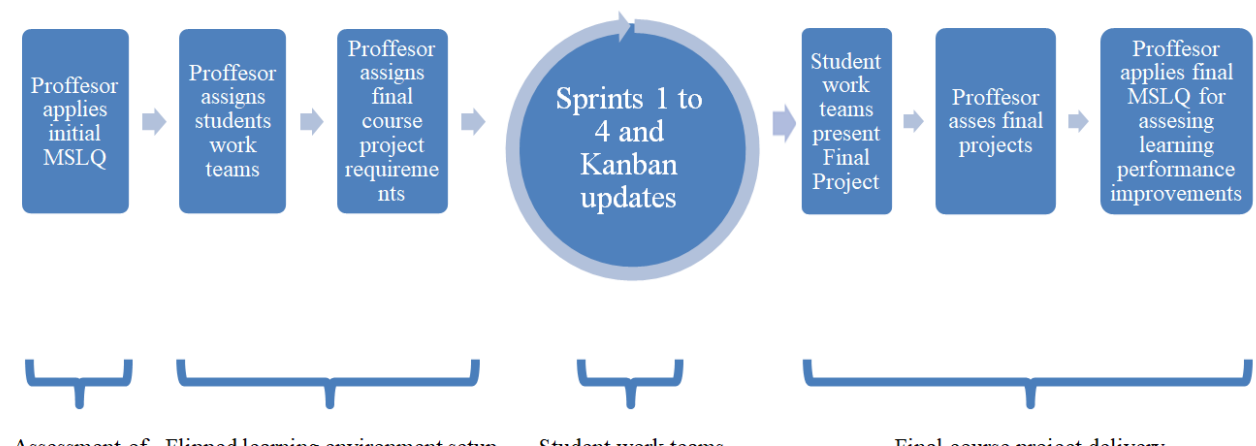

Assessment of Flipped learning environment setup student (Google Classroom + YouTube +
Student work teams Scrum and Kanban

learning strategies Google Drive) and final course project requirements

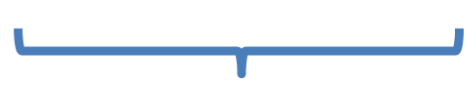

Final course project delivery, professor assess activities and final students learning strategies for improving assessment

Fig. 1 Flipped Learning Agile Methodology proposed for academic field.

The MSLQ, as propose (De Groot \& Pintrich, 1990; STEM Learning and research center, 2018), was applied at the beginning of thematic unit six and before implementing the FLA methodology in the student's group. Figure 2a shows the MSLQ students register form and Figure $2 b$ shows the MSLQ 0 to 7 questions to carry out the assessment. 


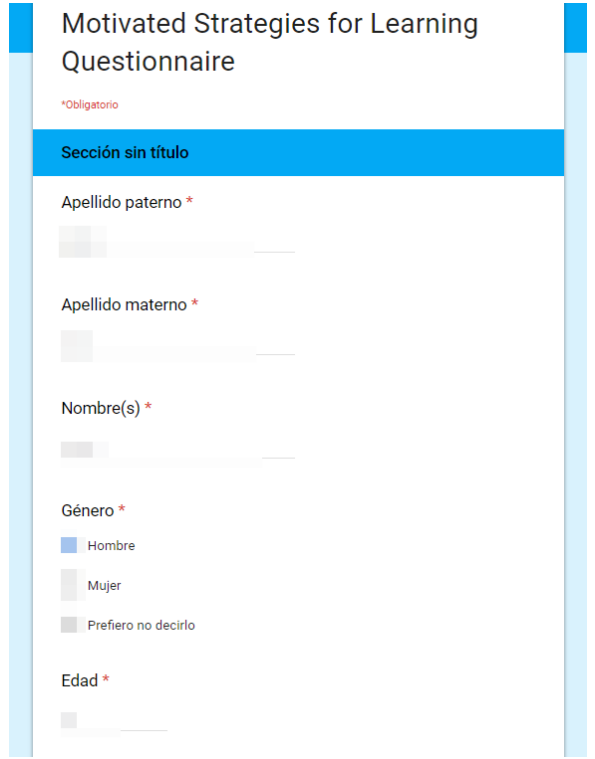

(a)

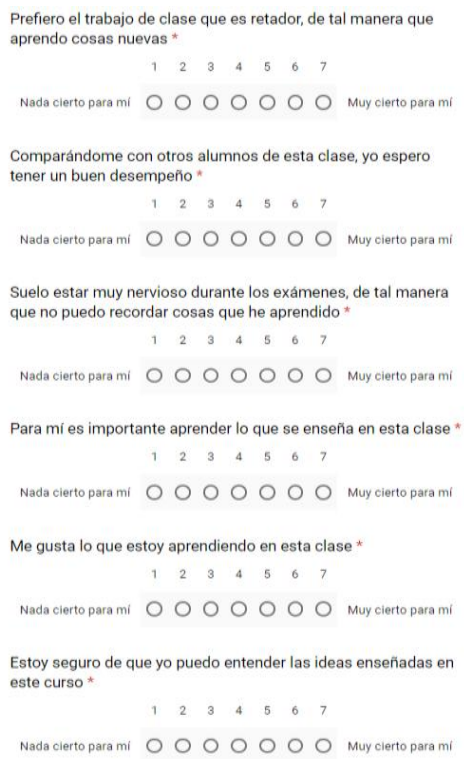

(b)

Fig. 2 MSLQ online form, (a) shows the student register and (b) the applied questions

After applying the MSLQ, professor publishes, by means of Google Classroom, the final project requirements and assessment policies. Then student's teams start to work in their own activities using the Scrum framework and Kanban board for scheduling the tasks. After finishing each sprint, students must update their Kanban board. Figure 3 shows an example of Kanban board implemented by a student's team.

\begin{tabular}{|c|c|c|c|c|c|c|}
\hline \multicolumn{7}{|c|}{ MACETA INTELIGENTE 2019} \\
\hline PENDIENTES & FECAA DE COMIENZO & FECHA DE VENCIMTENTO & EN PROCRESO & 8 COMPLETADO & COPLETADO & MOTAS \\
\hline conseguir materiales & $10 / 04 / 19$ & 03/05/19 & & $100 \%$ & 0 & electronicos \\
\hline conseguir materiales & $10 / 04 / 19$ & 03/05/19 & & $100 \%$ & 0 & para maceta \\
\hline realizar el diagrama & $10 / 04 / 19$ & 03/05/19 & realizar el diagrama & $75 \%$ & & \\
\hline simular circuito & $10 / 04 / 19$ & 03/05/19 & & $0 \%$ & & \\
\hline hacer maceta & $10 / 04 / 19$ & $03 / 05 / 19$ & hacer maceta & $75 \%$ & & \\
\hline armar maceta & $10 / 04 / 19$ & 03/05/19 & armar maceta & $25 \%$ & & \\
\hline comprobar maceta & $10 / 04 / 19$ & $03 / 05 / 19$ & & $0 \%$ & & \\
\hline programar arduino & $10 / 04 / 19$ & 03/05/19 & & $100 \%$ & 0 & \\
\hline armar filamento & $10 / 04 / 19$ & 03/05/19 & & $100 \%$ & 0 & \\
\hline conseguir planta & $10 / 04 / 19$ & 03/05/19 & & $100 \%$ & 0 & \\
\hline hacer calculos & $10 / 04 / 2019$ & 03/05/2019 & hacer calculos & $25 \%$ & & por el momento se ha complicado \\
\hline
\end{tabular}

Fig. 3 Kanban board implement by a team of students 
After all Scrum sprints were completed and the final project delivered, it was applied an MSLQ again to evaluate the students self-regulated learning strategies improvements. Table 1 shows how questions of the MSLQ evaluates the students learning components.

Table 1 MSLQ learning components index assessment

\begin{tabular}{lll}
\hline & Learning component & Questionnaire \\
\hline Motivational Beliefs & Self-Efficacy & $2,7,10,11,13,15,20,22,23$ \\
& Intrinsic Value & $1,5,6,9,12,17,18,21,25$ \\
& Test Anxiety & $3,14,24,27$ \\
Self-Regulated Learning & Cognitive Strategy Use & $30,31,33,35,36,38,39,42,44,47$ \\
Strategies & & $53,54,56$ \\
& Self-Regulation & $32,34,40,41,43,45,46,52,55$ \\
\hline
\end{tabular}

Using the learning components presented in Table 1, it is possible to assess the students self-regulated learning strategies and their motivational beliefs. A higher index in selfefficacy, intrinsic value, cognitive strategy use, and self-regulation is desired.

\section{Results and discussion}

A comparison of the results between the first and the last MSLQ (for motivational beliefs and self-regulated learning strategies) was carried out, as shown in Table 2.

Table 2 MSLQs results and its learning components rate change $(\Delta)$

\begin{tabular}{llccc}
\hline Strategy & MSLQ component & $1^{\text {st }}$ MSLQ group results & $2^{\text {nd }}$ MSLQ group results & $\Delta$ \\
\hline Motivational & Self-efficacy & 5.51 & 5.70 & +0.19 \\
beliefs & Intrinsic value & 5.49 & 5.64 & +0.15 \\
& Test anxiety & 5.34 & 5.54 & +0.20 \\
& Mean value & 5.45 & 5.63 & +0.18 \\
& Cognitive strategy use & 5.00 & 5.41 & $\mathbf{+ 0 . 4 1}$ \\
Self-regulated & Self-regulation & 4.90 & 5.35 & $\mathbf{+ 0 . 4 5}$ \\
& Mean value & 4.95 & 5.38 & $\mathbf{+ 0 . 4 3}$ \\
\hline
\end{tabular}


Agile methodologies and flipped classroom framework allowed the students to improve their self-regulated learning strategies, as well as their motivational learning beliefs as shown in Figure 4.

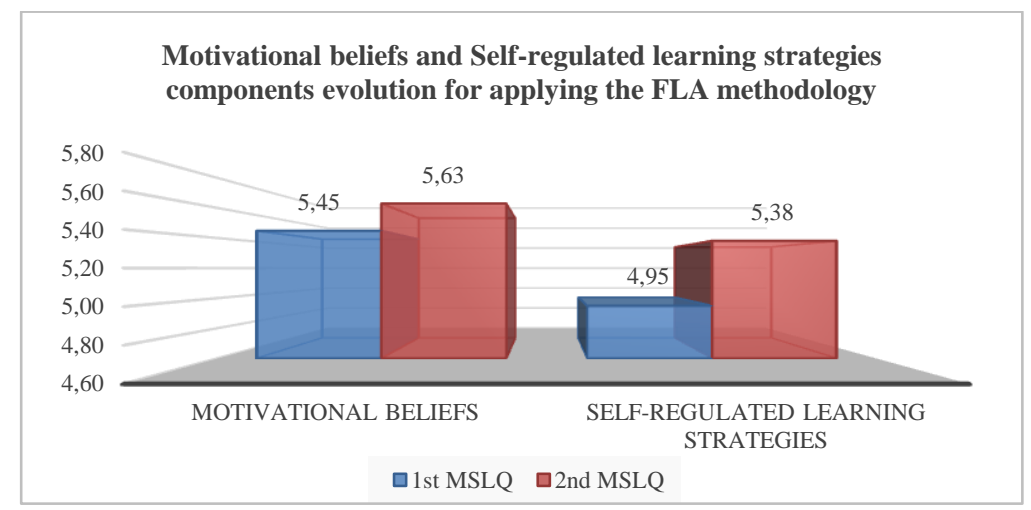

Fig. 4 Motivated Strategies for learning evolution after applying FLA methodology

According to results in Table 2, improvements in self-regulated learning strategies were noticed, changing the score from 4.95 to 5.38 points. While a less significant change was noticed in motivational beliefs strategies, scored from 5.45 to 5.63 points. About specific learning components, "self-regulation" score increases from 4.90 to 5.35 points. "Selfregulation" is related to an improvement in how students transform mental abilities in taskrelated skills (Zimmerman, 2001). "Cognitive strategy use" score increase from 5.00 to 5.41. "Cognitive strategy use assesses" how students learned to use new tools presented (Kauffman, 2004).

\section{Conclusions}

This paper presents the FLA methodology framework and its implementation results in a case of study for a student's group at the University of Guadalajara, México. Results of applying FLA methodology show that the method acts meanly on the self-regulated learning strategies and its related learning components. Main advantages obtained after applying FLA methodology are:

- $\quad$ Professors can improve significantly the self-regulated learning strategies in their students.

- Students increase self-confidence using the Scrum framework and the Kanban board improving their learning self-regulation. 


\section{References}

Ahmad, M. O., Dennehy, D., Conboy, K., \& Oivo, M. (2018). Kanban in software engineering: A systematic mapping study. Journal of Systems and Software, 137, 96-113. https://doi.org/10.1016/J.JSS.2017.11.045

Basoo-Aránguiz, M. (2018). Propuesta De Modelo Tecnologico Para Flipped Classroom. Revista Electrónica Educare, 22(2), 1-17. https://doi.org/10.15359/ree.22-2.2

Broadbent, J., \& Poon, W. L. (2015). Self-regulated learning strategies \& academic achievement in online higher education learning environments: A systematic review. Internet and Higher Education, 27, 1-13. https://doi.org/10.1016/j.iheduc.2015.04.007

Cakmakci, M., Kucukyasar, M., Aydin, E. S., Aktas, B., Sarikaya, M. B., \& Bekar, E. T. (2019). KANBAN Optimization in Relationship Between Industry 4.0 and Project Management Approach (pp. 210-227). https://doi.org/10.4018/978-1-5225-7865-9.ch011

De Groot, E. V, \& Pintrich, P. R. (1990). Motivational and Self-Regulated Learning Components of Classroom Academic Performance. Journal of Educational Psychology, 82(1), 33-40. https://doi.org/10.1037/0022-0663.82.1.33

Fernanda, S., Manuel, S., Germania, R., Samanta, C., Danilo, J., \& Patricio, A. (2018). Agile methodologies applied in teaching-learning process in engineering: A case of study. IEEE Global Engineering Education Conference, EDUCON, 2018-April, 1201-1207. https://doi.org/10.1109/EDUCON.2018.8363366

Hammarberg, M., \& Sundén, J. (2013). Kanban in action.

Hernandez, R., Version, D., \& Hernandez, R. (2019). Applicability of Agile and Scrum to ProductService Systems.

Judd, M., \& Blair, H. C. (2018). Agile and Lean Concepts for Teaching and Learning. Agile and Lean Concepts for Teaching and Learning. Springer Singapore. https://doi.org/10.1007/978-981-132751-3

Kauffman, D. F. (2004). Self-Regulated Learning in Web-Based Environments: Instructional Tools Designed to Facilitate Cognitive Strategy Use, Metacognitive Processing, and Motivational Beliefs. Journal of Educational Computing Research, 30(1-2), 139-161. https://doi.org/10.2190/AX2D-Y9VM-V7PX-0TAD

Leopold, K., \& Kaltenecker, S. (2015). Kanban change leadership. Wiley.

Maximini, D. (2015). The Scrum Culture: Introducing Agile Methods in Organizations. Retrieved from http://www.springer.com/series/10101

Nielsen, S. G., Johansen, G. G., \& Jørgensen, H. (2018). Peer learning in instrumental practicing. Frontiers in Psychology, 9(MAR). https://doi.org/10.3389/fpsyg.2018.00339

Schwaber, K. (2004). Agile project management with scrum. (M. Press, Ed.). Microsoft Press.

Stellman, A., \& Greene, J. (2016). Learning Agile: undestanding scrum, xp, lean, and kanban. 
STEM Learning and research center. (2018). Motivated Strategies for Learning Questionnaire (MSLQ) | STELAR - STEM Learning and Research Center. Retrieved May 5, 2019, from http://stelar.edc.org/instruments/motivated-strategies-learning-questionnaire-mslq

Tracy, B., Frog, E. T., \& Power, T. (2014). More Praise for Scrum: The Art of Doing Twice the Work in Half the Time.

Vaidya, S., Ambad, P., \& Bhosle, S. (2018). Industry 4.0 - A Glimpse. Procedia Manufacturing, 20, 233-238. https://doi.org/10.1016/j.promfg.2018.02.034

Xu, L. Da, Xu, E. L., \& Li, L. (2018). Industry 4.0: state of the art and future trends. International Journal of Production Research, 56(8), 2941-2962. https://doi.org/10.1080/00207543.2018.1444806

Zimmerman, B. J. (2001). Self-regulated Learning. International Encyclopedia of the Social \& Behavioral Sciences, 13855-13859. https://doi.org/10.1016/B0-08-043076-7/02465-7 